\title{
Strategi Pengembangan Industri Pariwisata di Kabupaten Sanggau
}

\author{
Febri Prima ${ }^{a}$, Noveicalistus H. Djanggu ${ }^{a}$, Utin Mardiyanti ${ }^{a}$, Siti Asri Heriyani Pertiwi ${ }^{a}$ \\ ${ }^{a}$ Universitas Tanjungpura, Indonesia
}

E-mail Korespondensi: febriprima@teknik.untan.ac.id

\begin{abstract}
Abstrak: Salah satu objek wisata unggulan di Kabupaten Sanggau adalah Pancur Aji, lokasi objek wisata berada di pusat ibukota Sanggau dan mudahnya akses menuju objek wisata. Wisata Pancur Aji memiliki daya tarik tersendiri yang menawarkan pemandangan air terjun, keberadaan flora dan fauna yang langka. Namun, dibalik besarnya potensi dari objek wisata tersebut masih terdapat permasalahan yang belum terselesaikan diantaranya, pengelolaan objek wisata masih belum optimal, masih banyak terdapat fasilitas yang tidak terawat seperi wahana permainan yang rusak. Tujuan penelitian ini adalah : (1) Untuk menentukan kelas potensi wisata berdasarkan Analisis Supply Demand; (2) Mengidentifikasi faktor internal (kekuatan dan kelemahan) dan faktor eksternal (peluang dan ancaman) yang berpengaruh terhadap pengembangan industri pariwisata Pancur Aji di Kabupaten Sanggau; (3) Mengetahui alternatif rencana strategi yang dapat diimplementasikan dalam pengembangan industri pariwisata Pancur Aji Kabupaten Sanggau. Metode analisis yang digunakan dalam penelitian ini adalah Analisis Supply Demand dan Analisis SWOT. Hasil Penelitian ini yaitu Pada Analisis Supply Objek Wisata Pancur Aji berada di kelas II (Potensi Sedang/Cukup Mendukung) dan pada Analisisi Demand berada di Kelas III (Potensi Rendah/Kurang Mendukung). Sedangkan pada Analisis SWOT dengan menggunakan Diagram Kartesius, Pancur Aji berada pada kuadran I maka sehingga strategi yang digunakan adalah strategi Strength-Opportunity (SO). Strategi pengembangan industri pariwisata Pancur Aji berdasarkan strategi SO diantaranya adalah: (a) Perlunya peningkatan akomodasi secara optimal dalam keberlangsungan kegiatan wisata agar wisatawan merasa nyaman untuk menikmati kawasan objek wisata Pancur Aji; (b) Menambahkan kegiatan atraksi wisata di Pancur Aji berupa Wisata Edukasi dengan meningkatkan promosi wisata untuk dapat menarik minat wisatawan untuk berkunjung sehingga wisata yang ditonjolkan di Pancur Aji bukan hanya wisata alam tapi wisata edukasi juga.; (c) Mendorong masyarakat untuk turut mempromosikan objek wisata kepada wisatawan dan dilakukan secara terus-menerus.
\end{abstract}

Kata Kunci: Analisis Supply Demand, Analisis SWOT, Industri Pariwisata, Strength-Oppurtunity (SO), Pancur Aji.

Abstract: One of the top attractions in Sanggau is Pancur Aji, the location of the attraction is in the center of the capital Sanggau and easy to access. Pancur Aji offers views of waterfalls, the sight of rare flora and fauna. However, behind the large potential of the attraction, there are still unresolved problems including poorly-managed attraction site, and broken facilities. The aim of the research is: (1) To identify the class of tourism potential based on Supply Demand Analysis; (2) To identify internal factors (strengths and weaknesses) and external factors (opportunities and threats) that affect the development of Pancur Aji in Sanggau; (3) To elaborate the alternative strategies to be implemented in the development of tourism industry Pancur Aji in Sanggau. The method of analysis that will be used in the study are Supply Demand Analysis and SWOT Analysis. The results of the study are in the Analysis of Supply of Pancur Aji is in class II (Medium Potential / Moderately Support) and in Demand Analysis is in Class III (Low Potential / Less Support). Meanwhile, in SWOT Analysis concluded that the value is in quadrant I so that the strategy used is Strength-Opportunity (SO) strategy. Pancur Aji tourism industry development strategy in Sanggau Regency based on SO strategy include: (a) The need to optimize accommodation to prolong the tourist activities so that tourists feel comfortable to enjoy at Pancur Aji area; (b) Increasing the promotion of educational tourism to attract tourists, so Pancur Aji tourist attraction not only shows natural attractions but there is educational tourism as well; (c) Encouraging the public to promote the attraction to tourists and be carried out continuously.

Keywords: Supply Demand Analysis, SWOT Analysis, Tourism Industry, Strength-Oppurtunity (SO), Pancur Aji.

How to cite (APA 6th Style):

Prima, Febri; Djanggu, Noveicalistus H; Mardiyanti, Utin; Pertiwi, Siti Asri Heriyanti.2021. Strategi Pengembangan Industri Pariwisata di Kabupaten Sanggau, 2(1), 17-28. doi: 10.26418/uniplan.v2i1.45898 


\section{PENDAHULUAN}

Sektor pariwisata merupakan salah satu sektor yang sangat penting untuk dikembangkan karena sektor pariwisata menjadi bagian dari sumber pendapatan daerah maupun negara. Berdasarkan UndangUndang Nomor 10 Tahun 2009 Pariwisata adalah berbagai macam kegiatan wisata dan didukung berbagai fasilitas serta layanan yang disediakan oleh masyarakat, pengusaha, pemerintah, dan pemerintah daerah. Sektor pariwisata memberikan kontribusi dengan meningkatnya pertumbuhan ekonomi karena mampu menghasilkan lapangan pekerjaa, mendorong berbagai sektor produksi, mendong kemajuan dalam usaha pembuatan atau peningkatan perbaikan pelabuhan, jalan raya, pengangkutan, serta mendorong pelaksanaan program kebersihan dan kesehatan, proyek sarana budaya, pelestarian lingkungan hidup yang dapat memberikan keuntungan maupun kesenangan baik kepada masyarakat setempat maupun wisatawan dari luar (Pendit, 1990).

Kabupaten Sanggau memiliki magnet pembangunan ekonomi yang besar untuk meningkatakan pendapatan daerah, dengan adanya kawasan pariwisata mampu memberikan peluang yang cukup besar dalam menciptakan lapangan kerja dan meningkatkan pertumbuhan ekonomi Kabupaten Sanggau. Kabupaten Sanggau terkenal akan bermacam-ragam tempat wisatanya, seperti wisata alam, sejarah dan budaya. Dari berbagai jenis tempat wisata yang ada salah satu wisata yang menjadi wisata unggulan di Kabupaten Sanggau adalah objek wisata Pancur Aji.

Pancur Aji adalah salah satu objek wisata di Kabupaten Sanggau yang merupakan kawasan perbukitan. Pancur Aji berada di pinggiran Teluk Sungai Kapuas bagian hilir atau pesisir barat, Kecamatan Kapuas. Obyek wisata ini memperlihatkan pemandangan air terjun yang masih alami jauh dari keramaian kota sehingga pengunjung bisa menikmati sensasi kesegaran saat berada di Pancur Aji. Selain itu, pengunjung juga dapat menikmati keindahan maupun keunikan dari flora fauna yang ada. Namun, dibalik besarnya potensi dari objek wisata tersebut masih terdapat permasalahan yang belum terselesaikan diantaranya pengelolaan objek wisata masih belum optimal masih banyak terdapat fasilitas yang tidak terawat seperi wahana permainan yang rusak.

Maka dari itu, pengembangan industri pariwisata merupakan hal yang penting untuk dikembangkan, selain memperkenalkan objek wisata yang ada juga dapat memberikan nilai tambah yang cukup menjanjikan. Untuk itu perlu adanya kerjasama baik dari pihak pemerintah, swasta dan masyarakat untuk saling membangun dan mendukung objek wisata dengan menyusun strategi yang tepat dan terarah agar dapat mencapai tujuan yang telah ditargetkan.

\section{DATA DAN METODE}

\subsection{Analisis Supply Demand}

Metode analisis yang digunakan dalam penelitian Strategi Pengembangan Industri Pariwisata di Kabupaten Sanggau sesuai dengan pendekatan dan metodologi penelitian adalah menggunakan analisis Supply Demand. Analisis Supply Demand adalah metode analisis yang memberikan penilaian evaluasi terhadap Obyek Daya Tarik Wisata (ODTW) di Kabupaten Sanggau salah satunya yaitu obyek wisata Pancur Aji. Identifikasi komponen untuk analisis supply demand dilakukan dengan menggunakan data eksisting yang didapat dari hasil observasi lapangan dan wawancara dengan wisatawan.

\subsection{Analisis SWOT}

Selain menggunakan Analisis Supply Demand, penelitian ini juga menggunakan Analisis SWOT.

Analisis SWOT adalah analisis untuk menentukan faktor internal maupun eksternal suatu obyek wisata yang akan dilakukan sebagai dasar untuk menyusun strategi dan program kerja. Analisis internal berupa penilaian terhadap faktor kekuatan (strength) dan kelemahan (weakness). Sedangkan analisis eksternal berupa penilaian terhadap faktor peluang (Oppurtunity) dan Ancaman (Threath). Analisis ini dapat memberikan gambaran tentang permasalahan yang dihadapi dan memberikan skenario untuk keadaan sekarang maupun untuk dimasa yang akan datang, sehingga dapat diperoleh konsep dan strategi yang menjadi alternatif dari suatu masalah. Untuk lebih jelasnya dapat dilihat pada gambar berikut : 
Tabel 1. Alternatif Strategi

\begin{tabular}{|c|c|c|}
\hline Faktor Internal & $\begin{array}{c}\text { Strenght (S) } \\
\text { Menentukan 5-10 faktor-faktor } \\
\text { kekuatan internal }\end{array}$ & $\begin{array}{c}\text { Weakness (W) } \\
\text { Menentukan 5-10 faktor-faktor } \\
\text { kelemahan internal }\end{array}$ \\
\hline $\begin{array}{c}\text { Opportunities (0) } \\
\text { Menentukan 5- 10 faktor- } \\
\text { faktor peluang eksternal }\end{array}$ & $\begin{array}{c}\text { Strategi S-O } \\
\text { Menyusun strategi untuk } \\
\text { memanfaatkan kekuatan dalam } \\
\text { upaya meraih peluang }\end{array}$ & $\begin{array}{c}\text { Strategi W-O } \\
\text { Menyusun strategi untuk } \\
\text { meminimalkan kelemahan dalam } \\
\text { upaya meraih peluang }\end{array}$ \\
\hline $\begin{array}{c}\text { Threats (T) } \\
\text { Menentukan 5-10 faktor- } \\
\text { faktor ancaman eksternal }\end{array}$ & $\begin{array}{c}\text { Strategi S-T } \\
\text { Menyusun strategi untuk } \\
\text { upanfaatkan kekuatan dalam }\end{array}$ & $\begin{array}{c}\text { Strategi W-T } \\
\text { Menyusun strategi untuk } \\
\text { meminimalkan kelemahan dalam } \\
\text { upaya menghadapi ancaman }\end{array}$ \\
\hline
\end{tabular}

Sumber : Rangkuti, 2001

\section{HASIL DAN PEMBAHASAN}

\subsection{Gambaran Umum Objek Wisata Pancur Aji di Kabupaten Sanggau}

Pancur Aji adalah salah satu objek wisata di Kabupaten Sanggau yang merupakan kawasan perbukitan. Pancur Aji berada di pinggiran Teluk Sungai Kapuas bagian hilir atau pesisir barat, Kecamatan Kapuas. Harga tiket masuk ke Pancur Aji juga tergolong murah, untuk orang dewasa di kenakan tarif sekitar 2500 dan anak-anak 1500 ditambah parkir kendaraan roda dua 2.500 dan 5.000 untuk mobil.

A. Atraksi wisata

Suatu objek wisata untuk dapat dikunjungi oleh wisatawan harus memenuhi kriteria atau syarat dalam pengembangan daerahnya, kriteria-kriteria tersebut diantaranya adalah something to see, something to do, dan something to buy (Yoeti, 1996). Berikut adalah penjelasan masing-masing syarat tersebut:

- Yang dapat dilihat

Wisata Pancur Aji merupakan wisata alam yang memperlihatkan pemandangan air terjun yang masih alami jauh dari keramaian kota sehingga pengunjung bisa menikmati sensasi kesegaran saat berada di Pancur Aji. Selain itu, pengunjung juga dapat menikmati keindahan maupun keunikan dari flora fauna yang ada.

- Yang dapat dilakukan

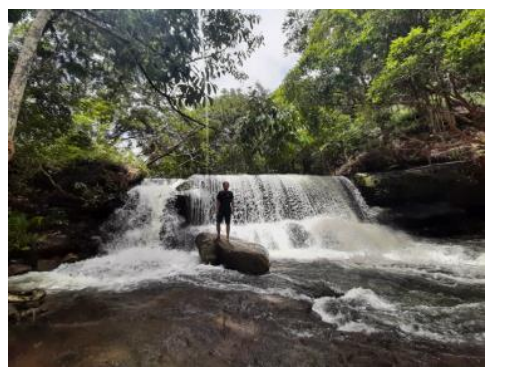

Gambar 1 Air Terjun Pancur Aji

Bagi para wisatawan yang berkunjung ke Pancur Aju dapat melakukan berbagai hal seperti mandi disekitar Air Terjun, menikmati pemandangan alam, bersantai dan berfoto-foto.

- Yang dapat dibeli

Belum terdapat souvernir khas yang dijual kepada para wisatawan di lokasi wisata Pancur Aji.

B. Aksesibilitas

Lokasi Pancur Aji terletak $\pm 6 \mathrm{~km}$ dari Kota Sanggau yang dapat ditempuh menggunakan transportasi darat. Sedangkan, untuk kondisi jalan menuju lokasi sudah cukup baik. 


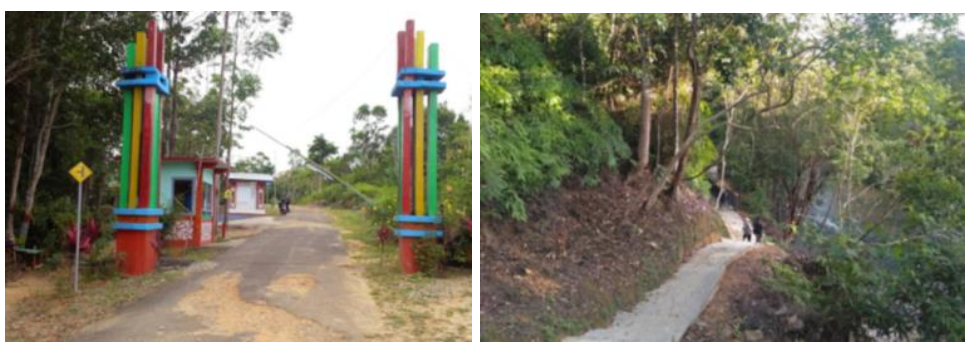

Gambar 2 Akses Jalan Menuju Wisata Pancur Aji

C. Sarana dan Prasarana

Pada Objek wisata Pancur Aji sudah terdapat sarana dasar seperti toilet, mushola, sarana persampahan. Sealin itu objek wisata ini juga terdapat sarana pendukung seperti jalur tracking berupa jalan setapak dan pagar pembatas, papan petunjuk jalan maupun papan peringatan bagi pengunjung.

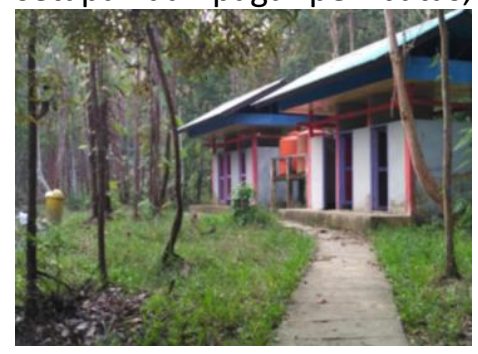

(a) Toilet

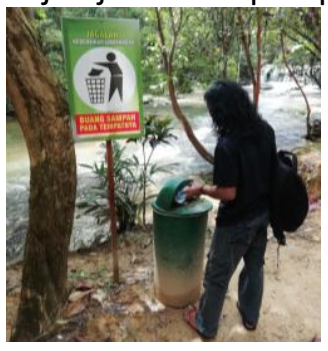

(b) Sarana Persampahan

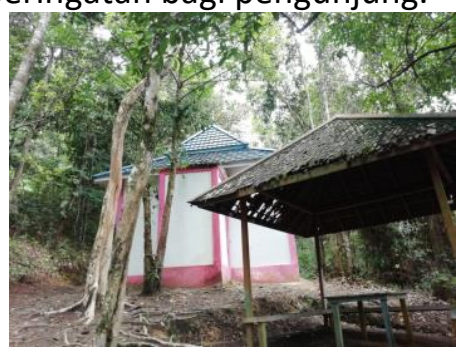

(c) Mushola

Gambar 3 Fasilitas Umum di Wisata Pancur Aji

\subsection{Analisis Supply Demand}

\section{A. Atraksi Wisata}

Daya tarik wisata adalah salah satu magnet suatu daerah untuk menarik wisatawan karena hal ini berkaitan dengan sesuatu yang dapat dilakukan, dapat dinikmati dan dapat dilihat. Berikut tabel analisis supply atraksi wisata Pancur Aji Kabupaten Sanggau:

Tabel 1 Analisis Supply Atraksi Wisata Pancur Aji Kabupaten Sanggau

\begin{tabular}{|c|c|c|c|}
\hline No & Parameter & Skoring & Kriteria \\
\hline \multicolumn{4}{|c|}{ Atraksi yang dapat dilihat } \\
\hline 1 & Keragaman ODTW & 3 & $\begin{array}{l}\text { Terdapat } 3 \text { - } 4 \text { daya tarik wisata (alam, minat khusus, dan } \\
\text { budaya) }\end{array}$ \\
\hline 2 & $\begin{array}{l}\text { Daya Tarik Wisata } \\
\text { Alam }\end{array}$ & 3 & $\begin{array}{l}\text { Terdapat } 3 \text { - } 4 \text { daya tarik wisata alam (flora fauna, keunikan } \\
\text { dan kekhasan ekosistem, budidaya sumber daya alam dan } \\
\text { lain-lain yang bersumber dari alam ) }\end{array}$ \\
\hline 3 & $\begin{array}{l}\text { Daya Tarik Minat } \\
\text { Khusus }\end{array}$ & 3 & $\begin{array}{l}\text { Terdapat } 3-4 \text { kriteria daya tarik minat khusus ( berburu, } \\
\text { mendaki gunung, agrowisata, tujuan pengobatan, dan lain } \\
\text { sebagainya) }\end{array}$ \\
\hline 4 & $\begin{array}{l}\text { Daya Tarik Wisata } \\
\text { Budaya }\end{array}$ & 2 & $\begin{array}{l}\text { Terdapat minimal } 2 \text { kriteria (peninggalan bangunan } \\
\text { bersejarah, peninggalan keagamaan, kegiatan dan cara } \\
\text { hidup masyarakat lokal dan lain sebagainya) }\end{array}$ \\
\hline 5 & Kesenian & 2 & Jumlah kesenian kurang dan tidak beragam \\
\hline 6 & Adat Istiadat & 2 & Jumlah tradisi kurang dan tidak beragam \\
\hline 7 & $\begin{array}{l}\text { Keunikan/ } \\
\text { Kekhasan }\end{array}$ & 3 & $\begin{array}{l}\text { Terdapat } 2 \text { Kriteria (nilai sejarah, kekhasan kebudayaan, } \\
\text { flora dan fauna, dan kekhasan lingkungan) }\end{array}$ \\
\hline \multicolumn{4}{|c|}{ Atraksi yang dapat dilakukan } \\
\hline 8 & $\begin{array}{l}\text { Variasi Aktifitas } \\
\text { Wisata }\end{array}$ & 4 & $\begin{array}{l}\text { Terdapat } 5 \text { aktifitas wisata yang dapat dilakukan (jalan- } \\
\text { jalan, berbelanja, bersepeda, ke museum, menikmati } \\
\text { makanan lokal yang khas, berfoto-foto, beribadah, }\end{array}$ \\
\hline
\end{tabular}




\begin{tabular}{|c|l|c|l|}
\hline No & Parameter & Skoring & \multicolumn{1}{c|}{ Kriteria } \\
\hline & & $\begin{array}{l}\text { menikmati wahana air, berolahraga, memancing, } \\
\text { menikmati hasil kebun dan lain sebagainya }\end{array}$ \\
\hline 9 & Event Wisata & 3 & $\begin{array}{l}\text { Terdapat minimal <3 macam event wisata dan rutin } \\
\text { dilaksanakan }\end{array}$ \\
\hline Atraksi yang dapat dibeli \\
\hline 10 & Cinderamata & 1 & Tidak tersedia \\
\hline $\begin{array}{c}\text { Total Skoring Atraksi } \\
\text { Wisata }\end{array}$ & $\mathbf{2 3}$ & Kelas III (Potensi ODTW Rendah/Kurang Mendukung) \\
\hline
\end{tabular}

Sumber: Hasil Analisis, 2021

Keterangan:Kelas I (Potensi ODTW Tinggi/Sangat Mendukung): $41-50$

Kelas II (Potensi ODTW Sedang/Cukup Mendukung): 31 - 40

Kelas III (Potensi ODTW Rendah/Kurang Mendukung): 21 - 30

Kelas IV (Tidak Mendukung): 10 - 20

Berdasarkan hasil analisis supply atraksi wisata dari 10 variabel yang diteliti, berarti memiliki skor maksimal 50 dan skor minimal 10. Tabel di atas menunjukkan bahwa nilai skor atraksi wisata adalah 23. Skor tersebut menunjukkan bahwa atraksi wisata yang ditawarkan memperoleh kelas III dengan potensi rendah/kurang mendukung.

\section{B. Aksesibilitas}

Aksesibilitas menjadi poin penting dalam berbagai kegiatan yaitu di bidang ekonomi, sosial, dan budaya. Kegiatan pariwisata memerlukan dukungan aksesibilitas yang baik. Jika obyek wisata tidak didukung dengan aksesibilitas yang baik maka obyek wisata yang ada akan sulit untuk menjadi industri pariwisata dan hal ini akan mempengaruhi keinginan seseorang untuk melakukan kegiatan pariwisata. Oleh karena itu, pelayanan angkutan pariwisata harus terintegrasi dengan angakutan antar ODTW, angkutan antar kota maupun antar kabupaten. Berikut analisis supply aksesibilitas Pancur Aji Kabupaten Sanggau:

Tabel 2 Analisis Supply Aksesibilitas Pancur Aji Kabupaten Sanggau

\begin{tabular}{|c|c|c|c|}
\hline No. & Parameter & Skoring & Kriteria \\
\hline 1 & Kondisi Jalan & 5 & $\begin{array}{l}\text { Kondisi jalan sangat baik, beraspal, jalanan tidak } \\
\text { bergelombang dan dapat dilalui berbagai jenis kendaraan }\end{array}$ \\
\hline 2 & Kendaraan umum & 2 & $\begin{array}{l}\text { Terdapat kendaraan umum ke objek wisata, jumlah } \\
\text { kendaraan umum }<10 \text { dengan jenis tidak beragam }\end{array}$ \\
\hline 3 & Transportasi & 4 & $\begin{array}{l}\text { Terdapat transportasi umum dengan jadwal tidak tetap, dan } \\
\text { jarak obyek wisat dekat dengan jaringan transportasi umum }\end{array}$ \\
\hline 4 & Waktu Tempuh & 5 & $0-30$ menit \\
\hline 5 & Biaya Transportasi & 5 & $\begin{array}{l}\text { Biaya transportasi yang dikeluarkan murah dan terjangkau } \\
\text { berdasarkan kriteria jarak yang ditentukan }\end{array}$ \\
\hline 6 & $\begin{array}{l}\text { Kondisi Terminal/ } \\
\text { Dermaga }\end{array}$ & 4 & $\begin{array}{l}\text { Terdapat terminal dan dermaga dekat dengan lokasi obyek } \\
\text { wisata dengan kondisi cukup bersih dan terawat dengan } \\
\text { angkutan yang terjadwal }\end{array}$ \\
\hline 7 & $\begin{array}{l}\text { Kelengkapan } \\
\text { Fasilitas Lalu Lintas }\end{array}$ & 5 & $\begin{array}{l}\text { Terdapat marka jalan, lampu penerang an jalan, lampu lalu } \\
\text { lintas, trotoar, rambu-rambu berupa rambu peringatan, } \\
\text { larangan, petunjuk dan rambu perintah, serta terdapat } \\
\text { papan nama jalan }\end{array}$ \\
\hline 8 & Akses Antar ODTW & 5 & $\begin{array}{l}\text { Terdapat akses jalan antara ODTW dengan kondisi jalan } \\
\text { sangat baik dan nyaman dilalui berbagai jenis kendaraan }\end{array}$ \\
\hline & $\begin{array}{c}\text { TOTAL SKOR } \\
\text { AKSESIBILITAS }\end{array}$ & 35 & Kelas I (Potensi ODTW Tinggi/Sangat Mendukung) \\
\hline
\end{tabular}

Sumber: Hasil Analisis, 2021

Keterangan: Kelas I (Potensi ODTW Tinggi/Sangat Mendukung): 33 - 40 
Kelas II (Potensi ODTW Sedang/Cukup Mendukung): 25 - 32

Kelas III (Potensi ODTW Rendah/Kurang Mendukung): 17 - 24

Kelas IV (Tidak Mendukung): $8-16$

Berdasarkan hasil analisis aksesibilitas wisata dari 8 variabel yang diteliti, berarti memiliki skor maksimal 40 dan skor minimal 8. Tabel di atas menunjukkan bahwa nilai skor aksesibilitas wisata adalah 35. Skor tersebut menunjukkan bahwa aksesibilitas wisata yang ditawarkan memperoleh kelas I dengan potensi tinggi/sangat mendukung.

\section{Sarana dan Prasarana}

Pariwisata tidak dapat dipisahkan dari akomodasi/penginapan serta sarana lainnya. Pariwisata dilakukan jauh dari rumah, memerlukan waktu lebih dari 24 jam. Oleh karena itu wisatawan membutuhkan tempat beristirahat, tidur, mandi, tempat makan, dan lain-lain. Tempat-tempat tersebut harus memenuhi syarat kebersihan/kesehatan, nyaman, dan memiliki akses tinggi ke lokasi daya tarik wisata. Disamping itu, fasilitas komunikasi dari/ke DTW pun menjadi pertimbangan bagi para wisatawan untuk mengunjungi DTW tertentu. Tingkat aksesibilitas dapat diperkuat dengan jalur nir-angkutan, yaitu jaringan telekomunikasi. Berikut analisis supply sarana dan prasarana wisata Pancur Aji Kabupaten Sanggau:

Tabel 3 Analisis Supply Sarana dan Prasarana Pancur Aji Kabupaten Sanggau

\begin{tabular}{|c|c|c|c|}
\hline No. & Parameter & Skoring & Kriteria \\
\hline 1 & Akomodasi & 3 & $\begin{array}{l}\text { Terdapat home stay dan wisma dengan pelayanan dan } \\
\text { fasilitas setara dengan hotel non bintang }\end{array}$ \\
\hline 2 & Toko Cinderamata & 1 & Tidak Tersedia \\
\hline 3 & $\begin{array}{l}\text { Rumah Makan/ } \\
\text { Restoran }\end{array}$ & 4 & $\begin{array}{l}\text { Terdapat restoran atau tempat makan dengan fasilitas } \\
\text { lengkap dan ditunjang oleh karyawan yang memadai }\end{array}$ \\
\hline 4 & Pusat Informasi & 4 & $\begin{array}{l}\text { Terdapat pusat informasi dengan kondisi layak digunakan } \\
\text { dan menyediakan peta wisata atau buku panduan wisata }\end{array}$ \\
\hline 5 & Sarana Hiburan & 3 & $\begin{array}{l}\text { Terdapat sarana hiburan di lokasi objek wisata, dengan } \\
\text { fasilitas sedang dan sarana yang cukup beragam }\end{array}$ \\
\hline 6 & Sarana Kesehatan & 4 & $\begin{array}{l}\text { Terdapat sarana kesehatan yang jarak lokasinya dekat } \\
\text { dengan objek wisata, dan pelayanan yang cukup lengkap }\end{array}$ \\
\hline 7 & Sarana Kebersihan & 4 & $\begin{array}{l}\text { Terdapat sarana kebersihan }<10 \text {, terdapat rambu-rambu } \\
\text { peringatan kebersihan dan dengan kualitas yang layak } \\
\text { digunakan }\end{array}$ \\
\hline 8 & $\begin{array}{l}\text { Sarana Parkir } \\
\text { Kendaraan }\end{array}$ & 5 & $\begin{array}{l}\text { Terdapat tempat parkir dengan lahan parkir yang luas, rapi, } \\
\text { terdapat penjagaan, memiliki batas-batas yang jelas, } \\
\text { menjamin kelancaran lalu lintas }\end{array}$ \\
\hline 9 & Sarana Air Bersih & 5 & $\begin{array}{l}\text { Kualitas air golongan A yang dapat diminum secara langsung } \\
\text { tanpa perlu diolah terlebih dahulu }\end{array}$ \\
\hline 10 & Perbankan & 4 & Terdapat sarana perbankan minimal 3 jenis bank \\
\hline 11 & Sarana Peribadatan & 5 & $\begin{array}{l}\text { Terdapat sarana peribadatan yang sangat dekat dengan } \\
\text { objek wisata dengan kondisis bersih dan terawat }\end{array}$ \\
\hline 12 & $\begin{array}{l}\text { Biro Perjalanan } \\
\text { Wisata }\end{array}$ & 4 & $\begin{array}{l}\text { Terdapat } 4-5 \text { biro perjalanan wisata yang menyediakan } \\
\text { paket wisata dengan harga sangat terjangkau }\end{array}$ \\
\hline 13 & $\begin{array}{l}\text { Kedai Makanan/ } \\
\text { Minuman }\end{array}$ & 5 & $\begin{array}{l}\text { Terdapat }>5 \text { kedai makanan/ minuman dengan bangunan } \\
\text { permanen dan jenis makanan/minuman sangat beragam }\end{array}$ \\
\hline 14 & Sarana Keamanan & 4 & $\begin{array}{l}\text { Terdapat sarana keamanan, terdapat rambu-rambu } \\
\text { peringatan ( } 4-5 \text { rambu), terdapat polisi pariwisata dengan } \\
\text { pemantauan, satuan pengamanan internal objek, dan lain } \\
\text { sebagainya }\end{array}$ \\
\hline 15 & Jaringan Listrik & 5 & $\begin{array}{l}\text { Tersedia jaringan listrik yang sangat baik di objek wisata dan } \\
\text { sekitarnya }\end{array}$ \\
\hline
\end{tabular}




\begin{tabular}{|c|l|c|l|}
\hline No. & \multicolumn{1}{|c|}{ Parameter } & Skoring & \multicolumn{1}{c|}{ Kriteria } \\
\hline 16 & $\begin{array}{l}\text { Rambu Penunjuk } \\
\text { Wisata }\end{array}$ & 5 & $\begin{array}{l}\text { Terdapat rambu penunjuk wisata dengan kondisi sangat } \\
\text { terawat dan dapat dibacan dengan sangat jelas }\end{array}$ \\
\hline 17 & Sarana Komunikasi & 5 & Terdapat jaringan operator seluler > 5 \\
\hline 18 & $\begin{array}{l}\text { Sarana Istirahat/ } \\
\text { Canopy }\end{array}$ & 5 & $\begin{array}{l}\text { Terdapat sarana istirahat/canopy > 5 dengan kondisi bersih } \\
\text { dan terawat }\end{array}$ \\
\hline 19 & Sarana Toilet/WC & 4 & $\begin{array}{l}\text { Terdapat sarana toilet/WC sejumlah 4-5 dekat dengan lokasi } \\
\text { objek wisata, dan dengan kondisi < 5 (bersih dan terawat, } \\
\text { pintu dapat dikunci, dipisah sesuai gender, terdapat lampu, } \\
\text { ventilasi udara yang baik, bangunan kokoh, tersedia air, dan } \\
\text { tinggi dinding minimal 1,5 m) }\end{array}$ \\
\hline $\begin{array}{c}\text { TOTAL SKORING SARANA } \\
\text { DAN PRASARANA }\end{array}$ & $\mathbf{7 9}$ & Kelas I (Potensi ODTW Tinggi/Sangat Mendukung) \\
\hline
\end{tabular}

Sumber: Hasil Analisis, 2021

Keterangan: Kelas I (Potensi ODTW Tinggi/Sangat Mendukung): 77-95

Kelas II (Potensi ODTW Sedang/Cukup Mendukung): 58 - 76

Kelas III (Potensi ODTW Rendah/Kurang Mendukung): 39 - 57

Kelas IV (Tidak Mendukung): 19 - 38

Berdasarkan hasil analisis sarana dan prasarana wisata dari 19 variabel yang diteliti, berarti memiliki skor maksimal 95 dan skor minimal 19. Tabel di atas menunjukkan bahwa nilai skor sarana dan prasarana wisata adalah 79. Skor tersebut menunjukkan bahwa sarana dan prasarana wisata yang ditawarkan memperoleh kelas I dengan potensi tinggi/sangat mendukung.

D. Kesimpulan Analisis Supply Pancur Aji Kabupaten Sanggau

Tabel 4. Rekapitulasi Nilai Atraksi Wisata, Aksesibilitas, Sarana dan Prasarana Pancur Aji Kabupaten Sanggau

\begin{tabular}{|c|l|c|c|}
\hline No & \multicolumn{1}{|c|}{ Komponen } & Variabel & Skor \\
\hline 1. & Atraksi Wisata & 10 & 23 \\
\hline 2. & Aksesibilitas & 8 & 35 \\
\hline 3. & Sarana dan Prasarana Wisata & 19 & 79 \\
\hline \multicolumn{2}{|c|}{ JUMLAH } & $\mathbf{3 7}$ & $\mathbf{1 3 7}$ \\
\hline
\end{tabular}

Sumber: Hasil Analisis, 2021

Keterangan: Kelas I (Potensi ODTW Tinggi/Sangat Mendukung): 149 - 185

Kelas II (Potensi ODTW Sedang/Cukup Mendukung): 112 - 148

Kelas III (Potensi ODTW Rendah/Kurang Mendukung): 75 - 111

Kelas IV (Tidak Mendukung): 37 - 74

Berdasarkan tabel diatas, skor yang didapat adalah 137. Hasil rekapitulasi nilai tersebut di rentang 112 - 148 berarti mendapat kelas II dengan potensi sedang. Dengan demikian secara keseluruhan dapat dikatakan bahwa komponen atraksi wisata, aksesibilitas, sarana dan prasarana wisata di Pancur Aji terbilang cukup mendukung.

E. Analisis Demand

Tipe aktivitas wisatawan yang mengunjungi Pancur Aji yaitu seperti untuk berekreasi, penelitian flora dan fauna, dan lain sebagainya. Sedangkan untuk pendapat dan tingkat kepuasan wisatawan serta waktu wisatawan dapat dilihat pada tabel berikut:

Tabel 5 Analisis Demand Pancur Aji Kabupaten Sanggau

\begin{tabular}{|c|l|c|l|}
\hline No. & \multicolumn{1}{|c|}{ Parameter } & Skoring & \multicolumn{1}{c|}{ Kriteria } \\
\hline 1 & $\begin{array}{l}\text { Pengalaman mengunjungi } \\
\text { wisata dalam 1 tahun terakhir }\end{array}$ & 3 & $5-7$ kali \\
\hline 2 & Lama tinggal wisatawan & 1 & $<12$ jam \\
\hline
\end{tabular}




\begin{tabular}{|c|l|c|l|}
\hline No. & \multicolumn{1}{|c|}{ Parameter } & Skoring & \multicolumn{1}{c|}{ Kriteria } \\
\hline 3 & $\begin{array}{l}\text { Bagaimana penilaian terhadap } \\
\text { obyek wisata }\end{array}$ & 4 & Baik \\
\hline 4 & Apakah pelayanan sudah baik & 4 & Baik \\
\hline \multicolumn{2}{|c|}{ Total Skoring Demand } & $\mathbf{1 2}$ & Kelas III (Potensi Rendah/Kurang Mendukung) \\
\hline
\end{tabular}

Sumber: Hasil Analisis, 2021

Keterangan: Kelas I (Potensi Tinggi/Sangat Mendukung): 17 - 20

Kelas II (Potensi Sedang/Cukup Mendukung): 13 - 16

Kelas III (Potensi Rendah/Kurang Mendukung): 9 - 12

Kelas IV (Tidak Mendukung): 4 - 8

Berdasarkan hasil analisis demand wisata dari 4 variabel yang diteliti, berarti memiliki skor maksimal 20 dan skor minimal 4. Tabel di atas menunjukkan bahwa nilai skor demand wisata adalah 12 . Skor tersebut menunjukkan bahwa untuk pendapat dan tingkat kepuasan wisatawan serta waktu wisatawan yang ditawarkan memperoleh kelas III dengan potensi rendah atau kurang mendukung.

3.3 Analisis SWOT Pengembangan Industri Pariwisata Pancur Aji di Kabupaten Sanggau

Tabel 6 Evaluasi Faktor Internal

\begin{tabular}{|c|c|c|c|c|}
\hline Faktor Internal & & Bobot & Rating & Skor \\
\hline \multirow[t]{7}{*}{ Strength } & A & 0.10 & 4 & 0.4 \\
\hline & $B$ & 0.10 & 4 & 0.4 \\
\hline & $\mathrm{C}$ & 0.08 & 3 & 0.24 \\
\hline & $\mathrm{D}$ & 0.07 & 3 & 0.21 \\
\hline & $E$ & 0.08 & 4 & 0.32 \\
\hline & $\mathrm{F}$ & 0.08 & 3 & 0.24 \\
\hline & $\mathrm{G}$ & 0.10 & 3 & 0.3 \\
\hline Total Strength & & & & 2.11 \\
\hline \multirow[t]{5}{*}{ Weakness } & $\mathrm{H}$ & 0.09 & 4 & 0.36 \\
\hline & 1 & 0.07 & 3 & 0.21 \\
\hline & $\mathrm{J}$ & 0.07 & 3 & 0.21 \\
\hline & $\mathrm{K}$ & 0.08 & 3 & 0.24 \\
\hline & $\mathrm{L}$ & 0.08 & 4 & 0.32 \\
\hline Total Weakness & & 1 & & 0.57 \\
\hline S-W & & 1.54 & & \\
\hline
\end{tabular}

Sumber: Hasil Analisis, 2021

Keterangan:A=Lokasi yang sangat strategis tidak jauh dari ibukota Sanggau, B= Lokasi objek wisata mudah dijangkau dengan menggunakan kendaraan roda dua maupun roda empat, $C=$ Biaya transportasi yang dikeluarkan murah, $\mathrm{D}=\mathrm{Sudah}$ terdapat fasilitas sarana prasarana yang cukup memadai, $\mathrm{E}=\mathrm{Adanya}$ peningkatan sarana dan prasarana objek wisata oleh Dispropar Kabupaten Sanggau, F=Sudah terdapat rambu-rambu peringatan seperti dipersimpangan, tanjakan dan turunan jalan, bebatuan yang licin agar para wisatawan dapat berhati-hati sehingga bisa menikmati objek wisata dengan lancar dan aman, G=Objek wisata Pancur Aji semakin tertata rapi dan bisa menjadi lokasi yang instagramable, $\mathrm{H}=$ Kurangnya kesadaran wisatawan dalam menjaga kebersihan lingkungan, $\mathrm{l}=$ - Sumber daya manusia masih kurang dalam segi kualitas maupun kuantitas, J=Tidak terdapat toko souvenir sebagai oleh-oleh bagi pengunjung, K=Minimnya atraksi wisata yang tersedia, L=Kurang beragamnya kendaraan umum menuju objek wisata.

Tabel 7 Evaluasi Faktor Eksternal

\begin{tabular}{|c|c|c|c|c|}
\hline Faktor Eksternal & & Bobot & Rating & Skor \\
\hline Opportunities & A & 0.11 & 4 & 0.44 \\
\hline & B & 0.09 & 3 & 0.27 \\
\hline & C & 0.08 & 3 & 0.24 \\
\hline & D & 0.09 & 3 & 0.27 \\
\hline
\end{tabular}




\begin{tabular}{|c|c|c|c|c|}
\hline Faktor Eksternal & & Bobot & Rating & Skor \\
\hline & $\mathrm{E}$ & 0.08 & 3 & 0.24 \\
\hline & $\mathrm{F}$ & 0.09 & 4 & 0.36 \\
\hline Total Opportunities & & & & $\mathbf{0 . 9 5}$ \\
\hline Threats & $\mathrm{G}$ & 0.10 & 4 & 0.4 \\
\hline & $\mathrm{H}$ & 0.09 & 3 & 0.27 \\
\hline & $\mathrm{I}$ & 0.08 & 3 & 0.24 \\
\hline & $\mathrm{J}$ & 0.09 & 4 & 0.36 \\
\hline & $\mathrm{K}$ & 0.10 & 3 & 0.3 \\
\hline Total Threats & & 1 & & $\mathbf{0 . 6 7}$ \\
\hline O-T & & $\mathbf{0 . 2 8}$ & & \\
\hline
\end{tabular}

Sumber: Hasil Analisis, 2021

Keterangan:A=Pertumbuhan perekonomian masyarakat sekitar objek wisata , $B=$ Berpotensi menjadi objek wisata penelitian/ edukasi,$C=$ Sudah terdapat peraturan daerah (Perda) yang mengatur pariwisata, $D=$ Perkembangan teknologi dan informasi yang kuat, $\mathrm{E}=$ Adanya dukungan pemerintah dalam pengembangan obyek wisata, $\mathrm{F}=$ Terdapat peningkatan dalam pengembangan sarana prasarana pendukung, G=Meningkatnya persaingan dengan objek wisata sejenis, $\mathrm{H}=$ - Belum optimalnya pembentukan kelompok sadar wisata atau pokdarwis, I= Ketidakpuasan wisatawan terhadap produk wisata yang ditawarkan, $\mathrm{J}=$ Meningkatnya minat warga untuk melakukan perjalanan wisata ke daerah lain, K=Ketidaksiapan dan kurangnya pemahaman masyarakat terhadap pengembangan pariwisata.

Berdasarkan Faktor IFAS dari Pengembangan Industri Pariwisata Pancur Aji di Kabupaten Sanggau yang diperoleh dari wawancara maka diperoleh faktor kekuatan dengan skor 2.11 dan Faktor Kelemahan 0.57, sementara itu berdasarkan Matrik EFAS dari faktor peluang diperoleh skor 0.95 dan Faktor Ancaman 0.67. Hasil skor kekuatan menunjukkan nilai lebih besar dari nilai skor kelemahan dengan selisih (1.54). Sedangkan hasil skor peluang menunukkan nilai lebih besar dibandingkan dengan nilai skor ancaman dengan selisih (0.28). Untuk lebih jelasnya dapat dilihat pada tabel rekapitulasi di bawah ini.

Tabel 8 Rekapitulasi Perhitungan Kekuatan, Kelemahan, Peluang dan Ancaman

\begin{tabular}{|c|c|c|}
\hline No. & Uraian & Nilai \\
\hline 1. & $\begin{array}{l}\text { Faktor Internal } \\
\text { - Kekuatan (Strength) } \\
\text { - Kelemahan (Weakness) }\end{array}$ & $\begin{array}{l}2,11 \\
0,57\end{array}$ \\
\hline 2. & $\begin{array}{l}\text { Faktor Eksternal } \\
\text { - Peluang (Oppurtunity) } \\
\text { - Ancaman (Threat) }\end{array}$ & $\begin{array}{l}0,95 \\
0,67\end{array}$ \\
\hline
\end{tabular}

\section{Sumber: Hasil Analisis, 2021}

Berdasarkan tabel di atas bahwa hasil selisih faktor internal dan faktor eksternal bernilai positif. Nilai hasil selisih tersebut dapat digambarkan dalam diagram kartesius SWOT. Berikut Diagram Kartesius yang dapat dilihat pada gambar di bawah ini. 


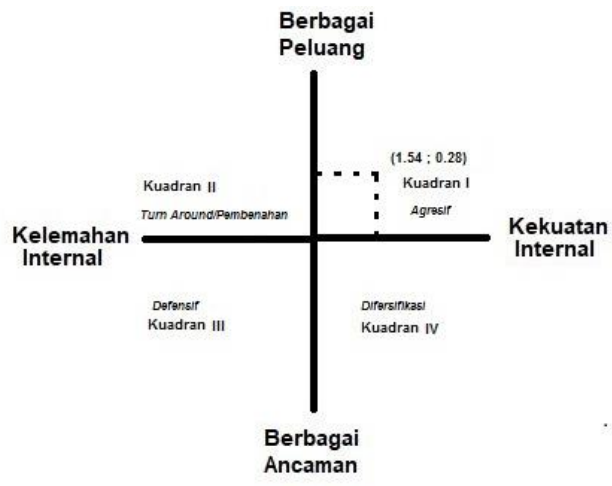

Gambar 4 Diagram Kartesius SWOT Industri Pengembang Pariwisata Pancur Aji Kabupaten Sanggau Sumber: Hasil Analisis, 2021

Berdasarkan hasil kuadran kartesius diatas kemudian diketahui bahwa Industri Pariwisata Pancur Aji di Kabupaten Sanggau termasuk dalam Kuadran I. Sehingga strategi yang digunakan ialah Agresif. Dari diagram pada gambar Analisa SWOT Pengembangan Industri Pariwisata Pancur Aji di Kabupaten Sanggau berada pada kuadran I berarti bahwa strategi yang digunakan adalah strategi Strength-Opportunity (SO). Strategi SO adalah strategi yang disusun untuk memanfaatkan kekuatan yang ada dalam upaya meraih peluang. Adapun Strategi Bisnis yang dapat dilakukan adalah dengan mengubah strategi sebelumnya.

\subsection{Kebijakan dan Strategi Pengembangan Industri Pariwisata Pancur Aji di Kabupaten Sanggau}

Berdasarkan analisis SWOT yang sudah dilakukan untuk mewujudkan tercapainya visi, misi, dan menjawab permasalahan yang ada, maka dapat dirumuskan beberapa strategi dalam pengembangan industri pariwata Pancur Aji yang dapat dilihat pada tabel Matriks SWOT di bawah ini.

Tabel 9 Matriks Analisis SWOT Pancur Aji Kabupaten Sanggau

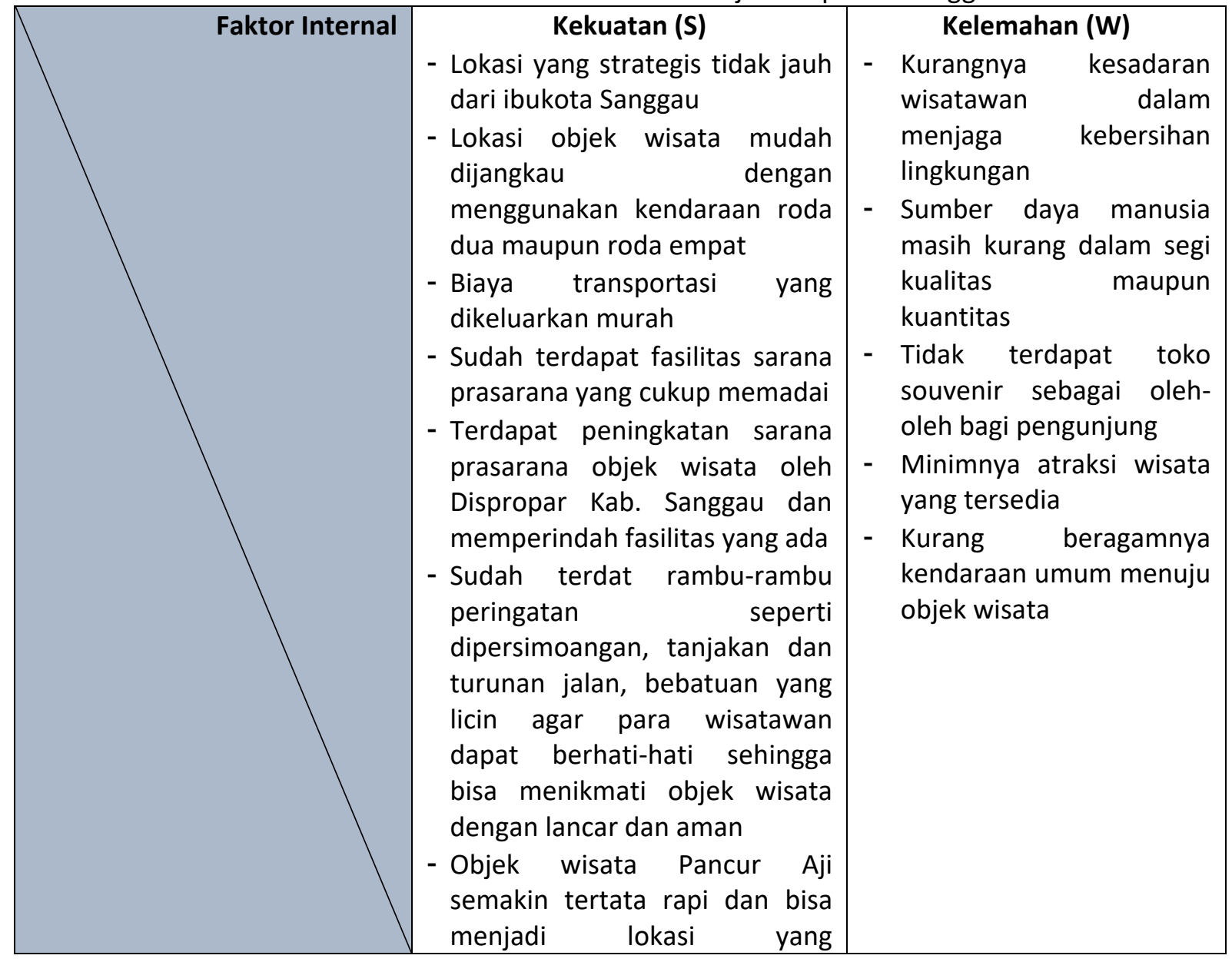




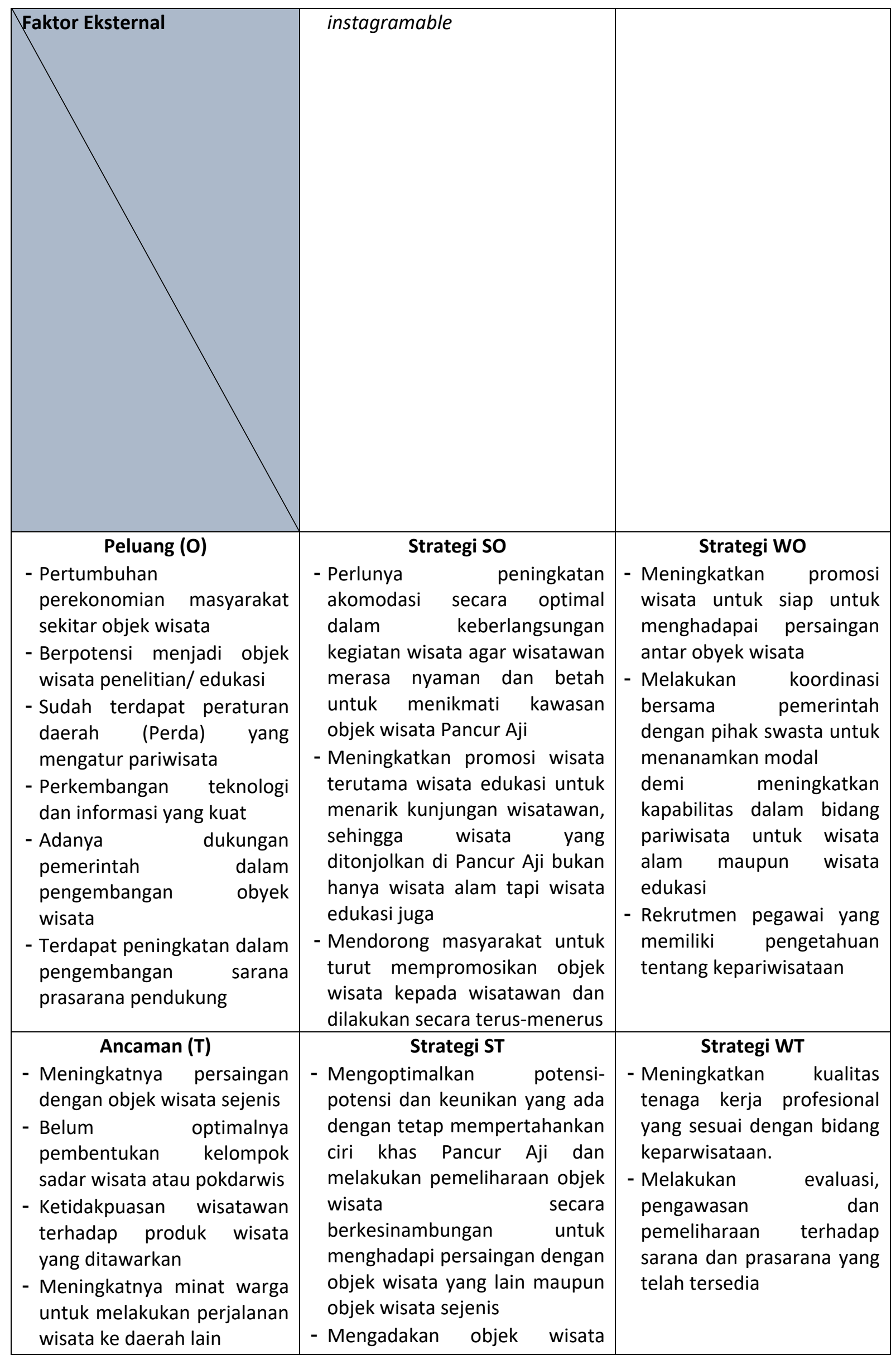




\begin{tabular}{|lr|lr|}
\hline - Ketidaksiapan & dan & pendamping & \\
kurangnya & pemahaman & Mengoptimalkan r peran & \\
masyarakat & terhadap & Pokdarwis untuk membantu & \\
pengembangan pariwisata & mengembangkan objek wisata & \\
& dan turut r membantu & mengembangakan program \\
& untuk wisata edukasi & \\
& & \\
& & \\
\end{tabular}

\section{KESIMPULAN}

Hasil dari penelitian yang telah disusun dapat ditarik beberapa kesimpulan yaitu sebagai berikut:

1. Objek Wisata Pancur Aji berada di Kelas II (Potensi Sedang/Cukup mendukung) untuk Analisis Supply dan Kelas III (Potensi Rendah/Kurang Mendukung) untuk Analisis Demand.

2. Industri Pariwisata Pancur Aji di Kabupaten Sanggau merupakan industri pariwisata yang memiliki potensi besar untuk dikembangkan, namun masih terdapat kelemahan-kelemahan yang perlu diminimalkan. Hal tersebut terlihat dari hasil analisis SWOT dan dengan menggunakan Diagram Kartesius, nilai berada di kuadran I sehingga strategi yang dapat digunakan adalah strategi StrengthOpportunity (SO).

3. Strategi pengembangan industri pariwisata Pancur Aji di Kabupaten Sanggau berdasarkan strategi SO diantaranya adalah:

a. Perlunya peningkatan akomodasi secara optimal dalam keberlangsungan kegiatan wisata agar wisatawan merasa nyaman dan betah untuk menikmati kawasan objek wisata Pancur Aji,

b. Menambahkan kegiatan atraksi wisata di Pancur Aji berupa Wisata Edukasi dengan meningkatkan promosi wisata untuk dapat menarik minat wisatawan untuk berkunjung sehingga wisata yang ditonjolkan di Pancur Aji bukan hanya wisata alam tapi wisata edukasi juga.

c.Mendorong masyarakat untuk turut mempromosikan objek wisata kepada wisatawan dan dilakukan secara terus-menerus.

\section{UCAPAN TERIMAKASIH}

Terima kasih kepada rekan-rekan yang turut serta membantu dalam penyusunan penelitaian ini sehingga dapat terselesaikan tepat waktu, dan juga kami ucapkan terima kasih kepada Universitas Tanjungpura yang telah memberikan kesempatan untuk menerbitkan penelitian ini.

\section{DAFTAR PUSTAKA}

Pendit, Nyoman S.1990.IImu Pariwisata: Sebuah Pengantar Perdana. Jakarta: Pradnya Paramita

Rangkuti, F. 1999. Analisis SWOT Teknik Membedah Kasus Bisnis-Reorientasi Konsep Perencanaan Strategis untuk Menghadappi Abad 21. Cet-11. Jakarta: P.T Gramedia Pustaka Utama

Undang-Undang Republik Indonesia Nomor 10 Tahun 2009 tentang Kepariwisataan

Yoeti, Oka A. 1986. Pengantar Ilmu Pariwisata. Bandung: Penerbit Angkasa 